\title{
Analysis of the Hazard, Vulnerability, and Exposure to the Risk of Flooding (Alba de Yeltes, Salamanca, Spain)
}

\author{
Sergio Veleda ${ }^{1}$, Antonio Martínez-Graña ${ }^{1, *}$, Fernando Santos-Francés ${ }^{2}$, \\ Javier Sánchez-San Roman ${ }^{1}$ and Marco Criado ${ }^{1}$ \\ 1 Department of Geology, Faculty of Sciences, University of Salamanca, Salamanca 37008, Spain; \\ veledaser@usal.es (S.V.); javisan@usal.es (J.S.-S.R.); marcocriado@usal.es (M.C.) \\ 2 Department of Soil Sciences, Faculty of Environmental Sciences, University of Salamanca, \\ Salamanca 37007, Spain; fsantos@usal.es \\ * Correspondence: amgranna@usal.es; Tel.: +34-923-294-496 \\ Academic Editor: Giacomo Cuttone \\ Received: 26 November 2016; Accepted: 3 February 2017; Published: 8 February 2017
}

\begin{abstract}
The present work has developed a method using GIS technology to evaluate the danger, vulnerability, and exposure to the risk of flooding in the Alba de Yeltes area (Salamanca, Spain). It is a non-structural measure for the prevention and mitigation of the risk of extraordinary flooding. After completing a full analysis of the physical environment (climate, geology, geomorphology, hydrology, hydrogeology, and land use), hydrological-hydraulic modeling was carried out using the GeoHecRas river analysis software. The results obtained from the analysis and the models have generated a danger map that facilitates the efficient evaluation of the spatial distribution of the different severity parameters (depth of the watersheet, current flow rate, and flood-prone areas). Also, map algebra and the databases associated with GIS tools, together with the vulnerability and exposure cartography, have allowed the risk to be analyzed in an integrate manner and the production of an environmental diagnostic map. The results of this study propose that there are inhabited areas close to the Yeltes-Morasverdes riverbed that have a high risk of flooding, indicating the need for proper land planning and the implementation of a series of measures that will help to reduce the risk of flooding and its impact.
\end{abstract}

Keywords: flood risk; environmental impacts; environmental diagnostic; environmental planning; GIS

\section{Introduction}

Traditionally, many permanently inhabited areas were located in floodplains, which are areas sensitive to fluctuating hydrological phenomena. These phenomena happen due to an unusual increase in the water flow of a riverbed, that may or may not lead to overflow. If temporary waterlogging of soils does occur in areas that are not normally saturated with water, this situation would be considered a flood.

This type of natural disaster is usually caused by events of extreme rainfall, where the effects can be either local or regional, and can have a great socioeconomic impact over time, in such a way that they transform the morphology of the riverbed, damage materials, or destroy infrastructures, in addition to causing the loss of human life [1,2].

To date, there are many studies on flood risk analysis that utilize geographic information systems, remote sensing, and hydraulic models, in a combined way [3-7].

The response to the risk of flooding has been the implementation of structural protection measures, such as dykes and dams, soil drainage, and controlled irrigation. 
On the other hand, flood prevention and the efficient management of flood risk is increasingly playing a more important role. Some of the measures that have been employed to minimize this risk include the regulation of urban planning and controlled land use. However, in the last few decades, these strategies have been complemented with practical land management, civil protection plans, early warning systems, the improvement of watersheds and forest systems, and measures to ensure sustainable planning [8].

The risk of flooding has been well outlined by the Directive 2007/60/CE, which describes flood assessment and management, and aims to reduce these types of risk. The main objective of this directive is to diminish the impact of flooding on human health, the environment, cultural patrimony, and economic activity.

This study aimed to generate a database that complied with the Directive INSPIRE (Directive 2007/2/CE), and was applied in the risk analysis of extraordinary flooding in Alba de Yeltes (Salamanca, Spain), developing a methodological sequence to identify the risk of flooding that could be used as a procedure in municipal environmental planning.

Moreover, the evolution of the watersheet for the various return periods $(t)(2,100$ and 500 years) for the Yeltes and Moraverdes rivers as they pass through Alba de Yeltes, was modelled. In addition, a flood risk map was generated in order to establish a zoning system for completing the diagnosis, identifying the environmental impact of the areas that show the highest level of danger, vulnerability, and exposure to risk, according to land use.

\section{Study Area}

The municipality of Alba de Yeltes is situated in the autonomous region of Castile \& Leon and the province of Salamanca, between the district of Ciudad Rodrigo and the sub-region of Campo del Yeltes. It is located $22 \mathrm{~km}$ from Ciudad Rodrigo and $72 \mathrm{~km}$ from Salamanca. The total surface area is $22.36 \mathrm{~km}^{2}$ and it has a population of 234 inhabitants $\left(10.47 \mathrm{hab} / \mathrm{km}^{2}\right)$. The altitude is $778 \mathrm{~m}$ above sea level, and the rivers within the area are the Yeltes and Morasverdes (Figure 1).

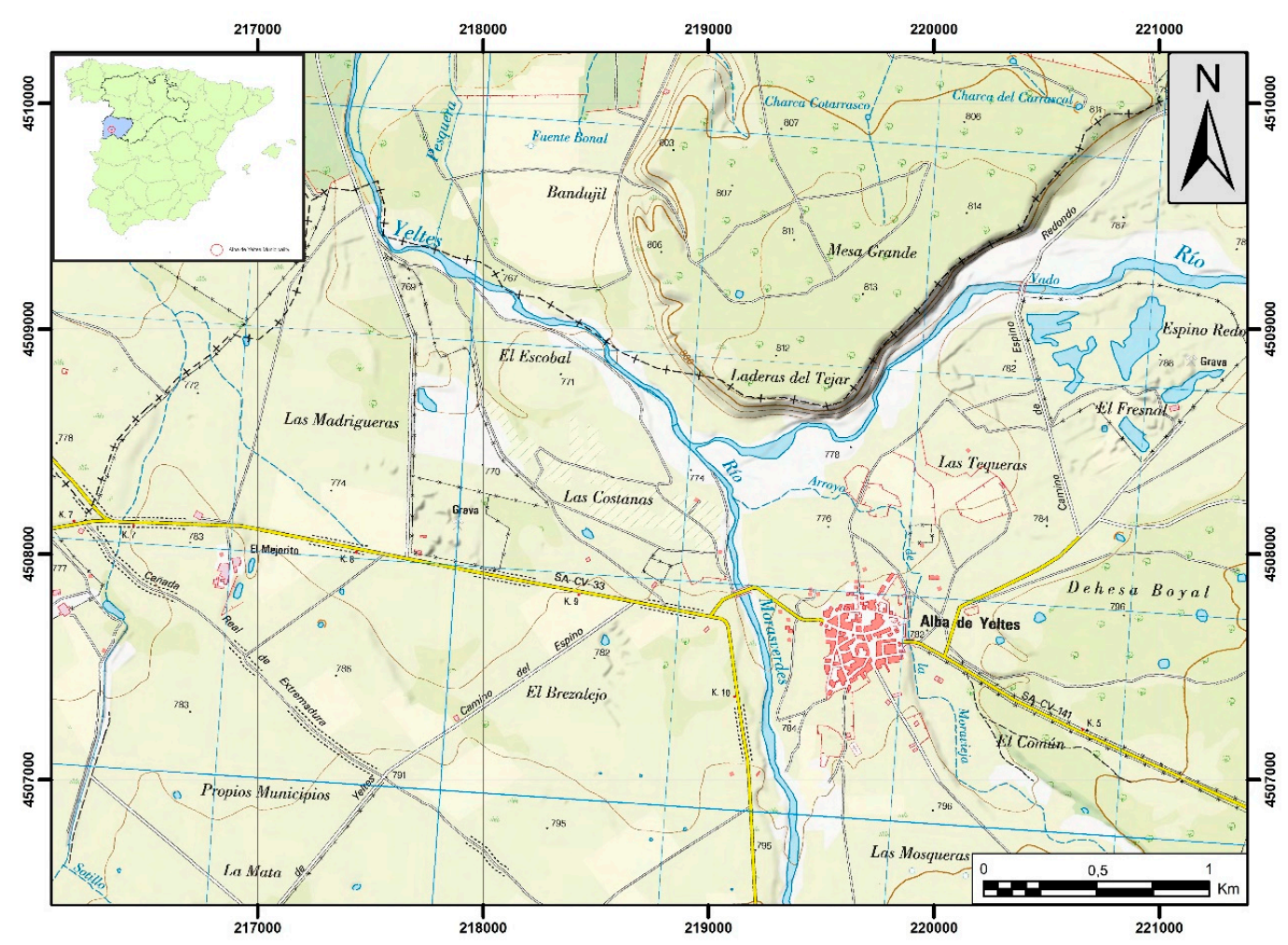

Figure 1. Localization of the study area. 


\section{Materials and Methods}

The methodology used to analyze the risk of flooding was based on the exploration of the physical environment, and was employed in a combined and complementary way for the hydrologic-hydraulic modeling using GIS. The results obtained from both the analysis and the modeling, permitted a danger, vulnerability, and exposure cartography to be generated, with the final aim of assessing the risk via an integrated analysis and obtaining an environmental diagnostics cartography (Figure 2).

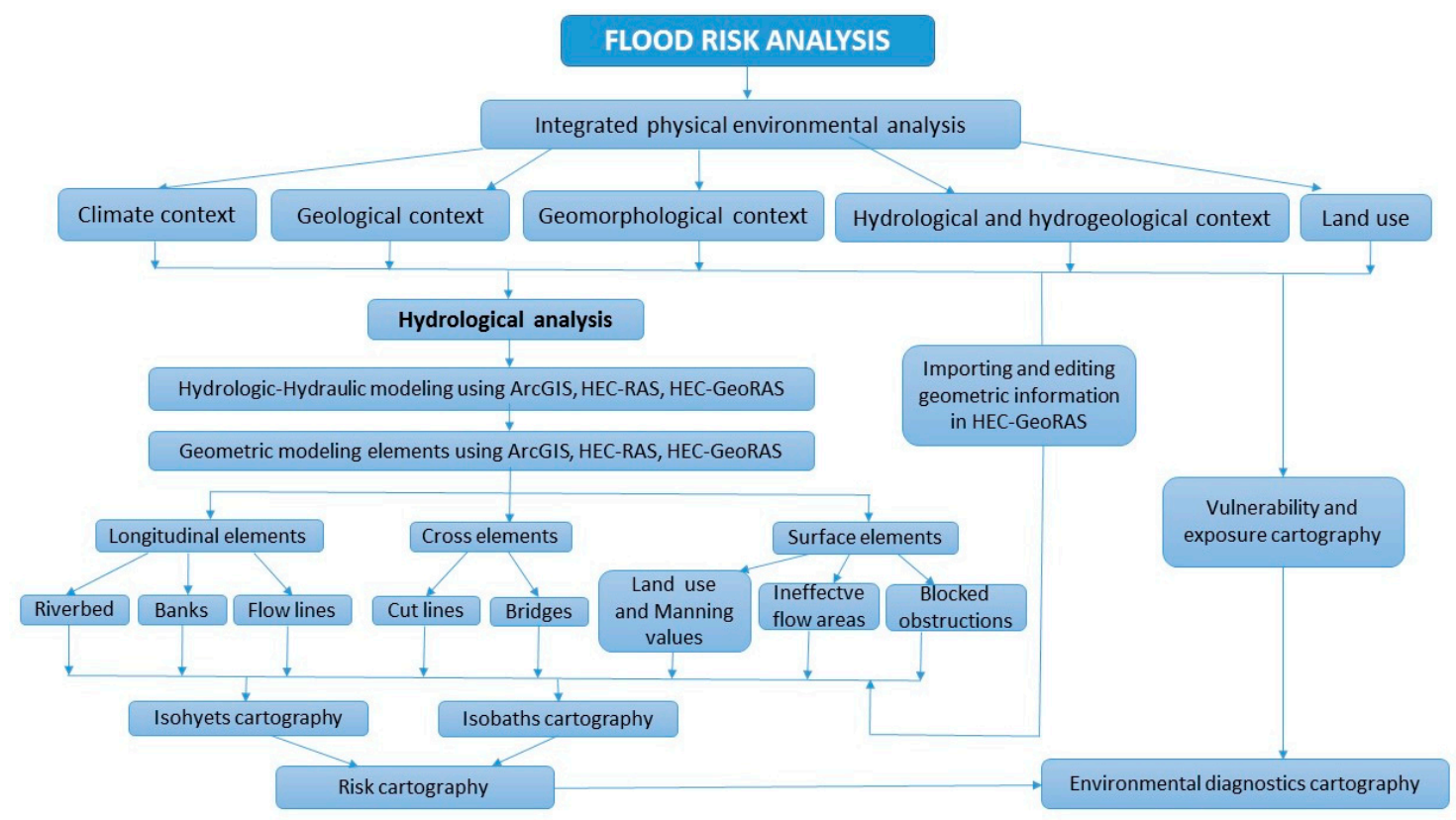

Figure 2. Methodology followed for analyzing flood risk.

\subsection{Integrated Analysis of the Physical Environment}

In order to carry out a precise flood risk analysis, a complete exploration of the study area is required, and the resulting data should be used in a combined and complementary way to generate the hydrological model.

A brief description of the various parameters included within the study, such as the climate, geology, geomorphology, hydrology, geohydrology, and land use, are described below.

According to the Köppen classification, the climate of the study area is Mediterranean (Csb), and according to the Papadakis classification, the type of summer and winter corresponds to Maize (M) and Oats $(\mathrm{O})$, respectively.

The values for the average annual precipitation are around $614 \mathrm{~mm}$, and the average annual temperature is $12.40^{\circ} \mathrm{C}$.

The geology of the area pertains to the Iberian Massif or Peninsula, and in particular, to the extreme south of Lotze's Galician-Castilian Zone and the central-north of Julivert's Central Iberian Zone.

The age of the material is Cenozoic, and is divided into materials of the Paleogene and Neogene period (Eocene-Oligocene-Miocene). They have a sludgy alluvial nature and contain sands, clays, and clasts made up of quartz and/or feldspar, that are mixed with conglomerates containing quartz pebbles (sometimes shales, slates, or feldspars).

Additionally, there are some white hydromorphic soils from carbonate and limestone, and iron oxides. In addition, materials from the Quaternary period (Pleistocene-Holocene), of a sandy, loamy, and clayey nature, are present. The alluvial terraces can be attributed to both the Pleistocene, and more recent periods, and contain gravel and pebbles imbedded in a sandy-loamy matrix from the Holocene period, that extends until present day, constituting the valley bottoms and floodplains. 
In this type of study, the geomorphological features, which play a relevant part in the study of the origin, propagation, and the effects of the flood plains, are of special importance and are manifested as three separate factors:

(1) Morphographic: they are obtained from morphometric parameters (slopes, roughness, orientations, topographic profiles, etc.). These parameters have been obtained, using GIS, from a digital terrain model, with a spatial resolution of $5 \mathrm{~m}$ using LIDAR (light detection and ranging). The study area presents rivers with meandering forms, as is normal in the middle sectors, which leads to a more rapid occupation of the floodplain, with a more unstable channel, whose meanders can be insolated.

(2) Morphodynamic: the variation of velocity fields affects the spatial distribution of points where erosion, transport, and sedimentation phenomena occur, and results in morphological characteristics, such as abandoned meanders and channel bars.

(3) Morphoevolution: caused by an increase in the depth of the riverbed, generating the different terrace levels. In our study area, these terraced sequences are generated by the tectonic elevation of the Central System, which moves northwards towards the channels. This generates asymmetric valleys, where the terraces are deposited in the left margin, important escarpments are produced in the right, without the deposit of terraces. The neotectonic movement produces $\mathrm{N}-\mathrm{S}$ fractures, accentuating the sinuosity of the fluvial course. These fractures are observed in the escarpments, and do not condition the general fluvial tracing.

All of these aspects result in characteristic geomorphological formations, as follows:

There are extensive platforms of deposits that are located at the tip of the alluvial fans, called "rañas" (Neogene). There are two well-differentiated horizons: an upper horizon made of coarse sands, gravel, and red pebbles from iron oxides; and a lower horizon made up of a band of clays and iron oxides, which have a deposition thickness of 1-2 m. Over time, another horizon appears due to the accumulation of more clay, which is between 2.58 and 1.8 million years old (Pleistocene). There are also many superficial formations of recently deposited materials (Quaternary), and hillside deposits, sandy colluvials, alluvial fans, and debris cones (gravel, sands, and silts). These give rise to almost flat surfaces, called foothills and glacis. Additionally, there are flat valley bottoms associated with drainage and endorheic formations, which are areas of temporary waterlogging, such as "navas" or long valleys with flat bottoms. There are also various fluvial terraces with Quaternary sediments and hillside colluvial-type deposits. Lastly, the escarpment of the Yeltes River shows signs of erosion that causes the riverbed to become displaced, towards the right bank. On the left bank, sedimentation occurs, causing wide sequences of terraces and generating an asymmetric valley [9-11].

Moreover, there are geoforms of simple erosive flows, called "slumps"; processes of creeping and gullies that are formed by sheet flows on hillsides, being more abundant on the lower part. There are also rotational and translational landslides, and cracks that can initiate further landslides [12-14].

Within a hydrological context, it should be mentioned that the hydrographic network where the study area is located pertains to the Duero River Hydrographic Basin, and in particular, within the Agueda sub-basin. This area also includes the Yeltes River, its tributary, the Morasverdes, and some temporary streams.

The following section deals with the permeability of the materials. The 21 hydrogeological units (H.U.) defined within the Duero Basin of the study area, are located in H.U. 19, a denomination of the Ciudad Rodrigo sub-basin. The materials included within this area are of the detrital type (sandstones, conglomerates, sands, muds), with a confined/semi-confined behavior, and with permeability and intergranular porosity.

Finally, it should be mentioned that the identification of land use was carried out using the European Corine Land Cover with maps at a scale of 1:50,000. Of these, the primary sector (livestock farming and agriculture) predominates, as well as some areas with extractive activity (gravel pits). The 
estimated surface area dedicated to different types of land uses, and the corresponding percentages, are shown in Table 1.

Table 1. Major land uses and area calculated with GIS.

\begin{tabular}{ccc}
\hline Land Use & Area (Ha) & Area (\%) \\
\hline Agricultural crops & 971.483434 & 14.1 \\
Cultivated pasture & 61.155725 & 0.9 \\
Pasture of abandoned crops & 157.196236 & 2.3 \\
Extractive activity (gravel deposit) & 145.02235 & 2.1 \\
Primary urban land & 7.865506 & 0.1 \\
Urban residential land & 23.240148 & 0.3 \\
Open woodland & 3025.333722 & 43.9 \\
Closed woodland & 331.623337 & 4.8 \\
Scrub & 366.003487 & 5.3 \\
Pasture & 1800.128056 & 26.1 \\
Bare land & 9.684563 & 0.1 \\
TOTAL & 6898.736564 & 100.0 \\
\hline
\end{tabular}

To better analyze the physical environment, cartographies illustrating the geology, geomorphology, elevation, and land permeability and land use, were generated (Figure 3).
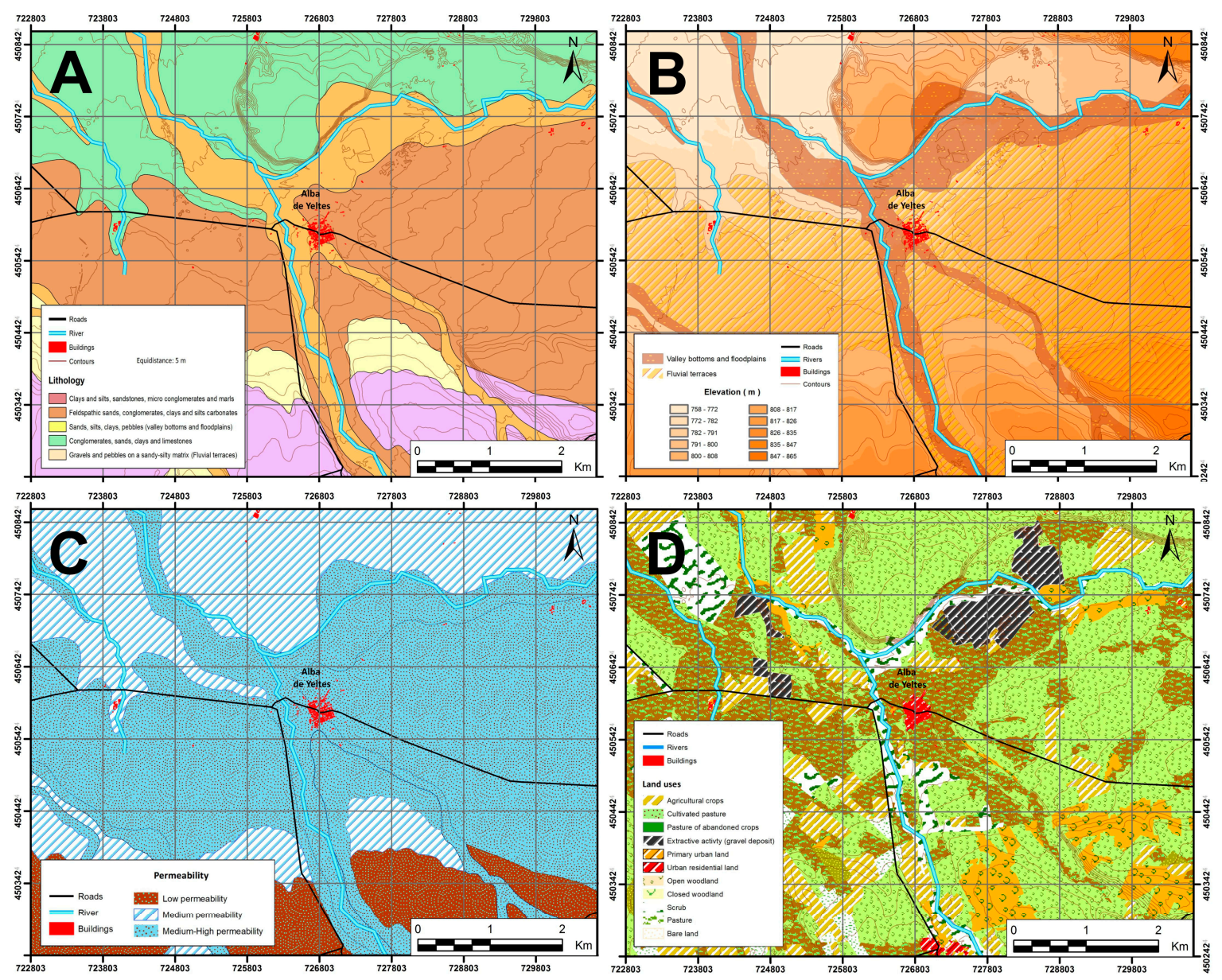

Figure 3. (A) Maps: geological; (B) geomorphological and elevation; (C) permeability; and (D) land use. 


\subsection{Hydrological Analysis}

A hydrological analysis was carried out using geometric modeling of the elements of the Yeltes and Morasverdes riverbeds, using GIS (ArcGIS 10.1) and the Hydrologic Engineering Centers River Analysis System (HEC-RAS) program, together with the extension HEC-GeoRAS. The analysis was concentrated on obtaining riverbed geometric information, and the exporting and importing of data between HEC-RAS and ArcMap [15,16].

The objective of this analysis was to provide information regarding the distribution of the height of the watersheet, and the velocity of each of the return periods considered $(2,100$, and 500 years), in order to create an isobaths and isotach cartography. With this information, a hazard cartography could be generated that, together with the vulnerability and exposure maps, based on the integrated analysis of the physical environment, permits the construction of an environmental diagnostic cartography, showing the zoning of the impact associated with this risk.

\subsubsection{Trace of the Longitudinal Elements}

For modeling the riverbeds in the study area, the course of the riverbed's axis and its direction (Figure 4A), which is always downstream, are traced. Furthermore, the area in which the water flow normally runs along the delineation of the river banks, is demarcated (Figure 4B).
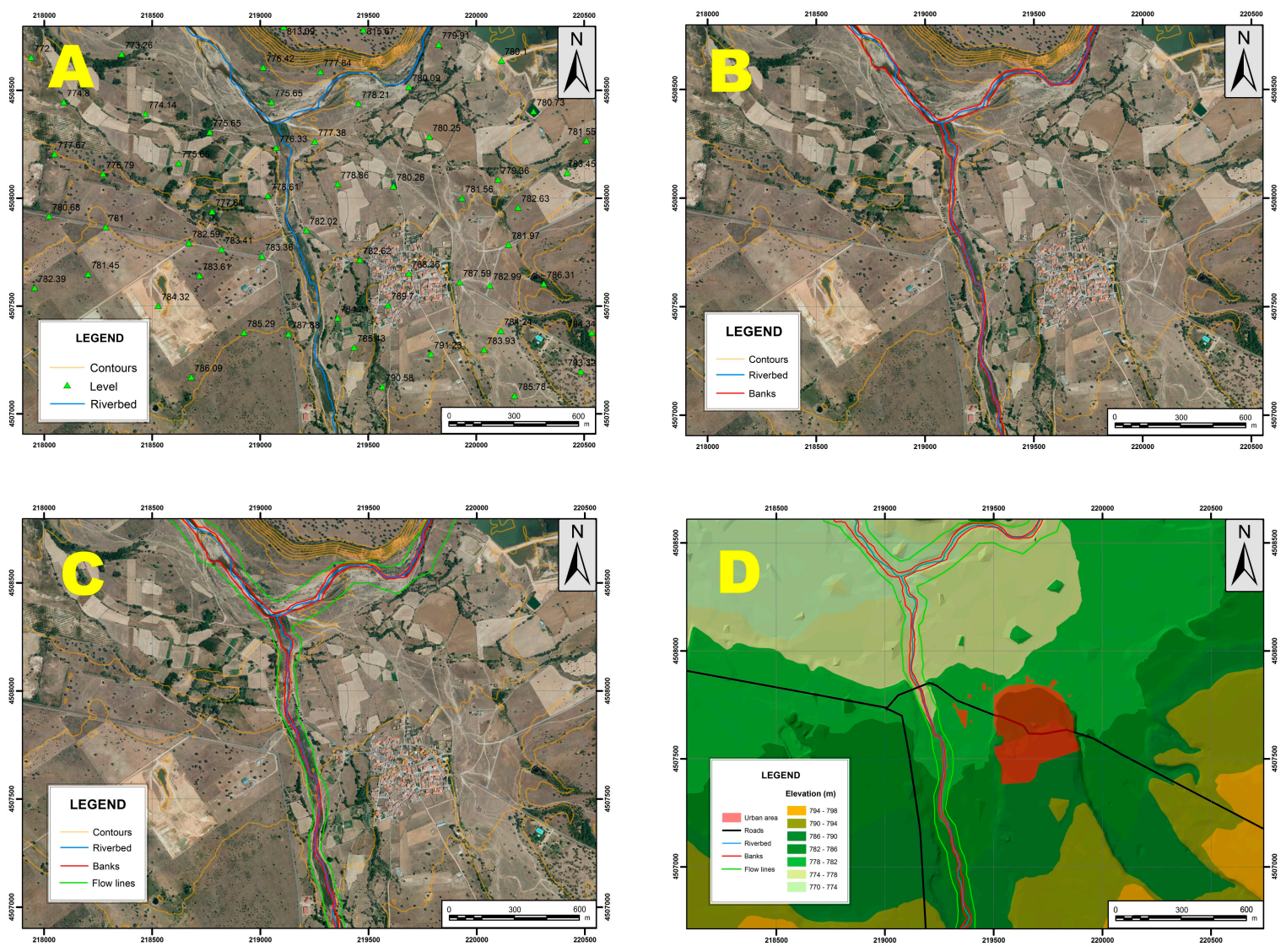

Figure 4. (A) Digitalization of the riverbed axis; (B) river banks; (C) flow lines; and (D) the digitalization of all of the longitudinal parameters overlaid on the TIN model. 
Flow lines are also needed for defining the longitudinal geometry of the riverbed (Figure 4C), on both sides, which serve as a guide for the longitudinal localization of the transversal sections. The orthophotographs are used as a reference for all of these parameters. In addition, all of the longitudinal elements can be visualized when overlaid on the TIN model (Figure 4D).

\subsubsection{Trace of the Cross Elements}

In this second phase of ArcGIS, the transversal elements were defined, and were perpendicular to the direction of flow. These elements were necessary for defining the geometry of the riverbed. First, the transversal sections perpendicular to the riverbed axis, which extend the full length of the flood plain, were edited (Figure 5A). These elements are essential for the subsequent execution with HEC-RAS, and allow the altitudinal information regarding the land to be extracted, which is then used as a reference to define the channel's geometry.
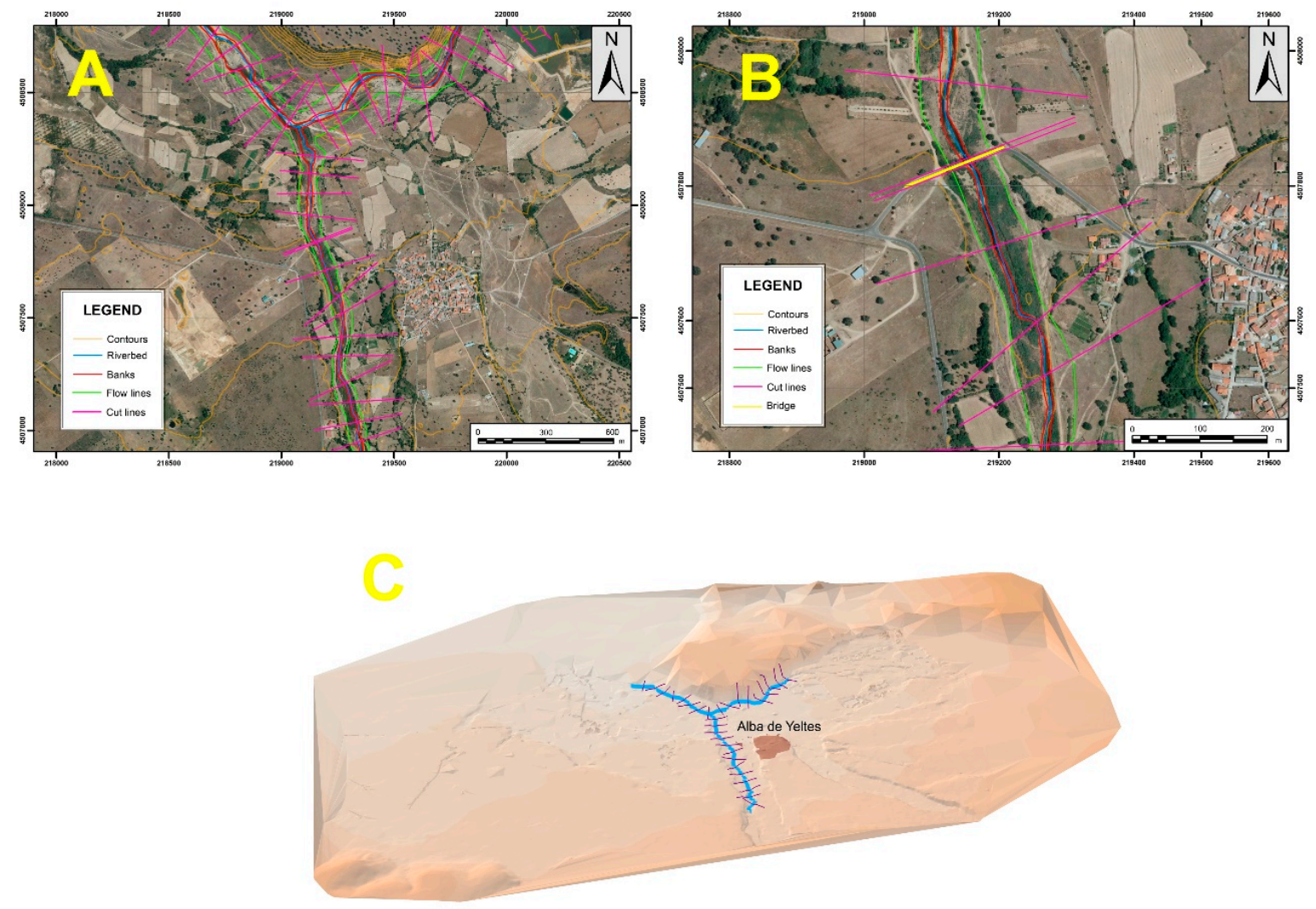

Figure 5. Digitalization of $(A)$ the transversal sections $(B)$ of the bridge and $(C)$ the $3 D$ view of the transversal sections using ArcScene.

Among the other transversal elements perpendicular to the riverbed axis, found within the stretch of the river Moraverdes and located quite close to the study area, was a bridge that was digitalized with the help of the orthophotographs (Figure 5B). Also, a view of the transversal sections was generated using ArcScene (Figure 5C). Afterwards, the geometric structure of the section of the bridge over the riverbed was defined using HEC-RAS. 


\subsubsection{Trace of the Surface Elements}

In this third phase, each of the transversal sections was assigned a corresponding Manning's roughness coefficient $(n)$, which relates the surface resistance caused by the river bank (depending of the presence and type of vegetation), to the water flow. This is a fundamental requisite in the analysis of floods. In the modeling of river floods, wooded areas or highly built-up areas present a greater resistance to the movement of water and therefore, have higher $n$ values. In contrast, areas with less buildings, asphalted areas, or areas with crops, present less resistance and thus, the $n$ values are lower.

Different $n$ values were assigned to each land use included within the study area, which were digitalized and overlaid on the orthophotographs (Figure 6A), as shown in the table of attributes.
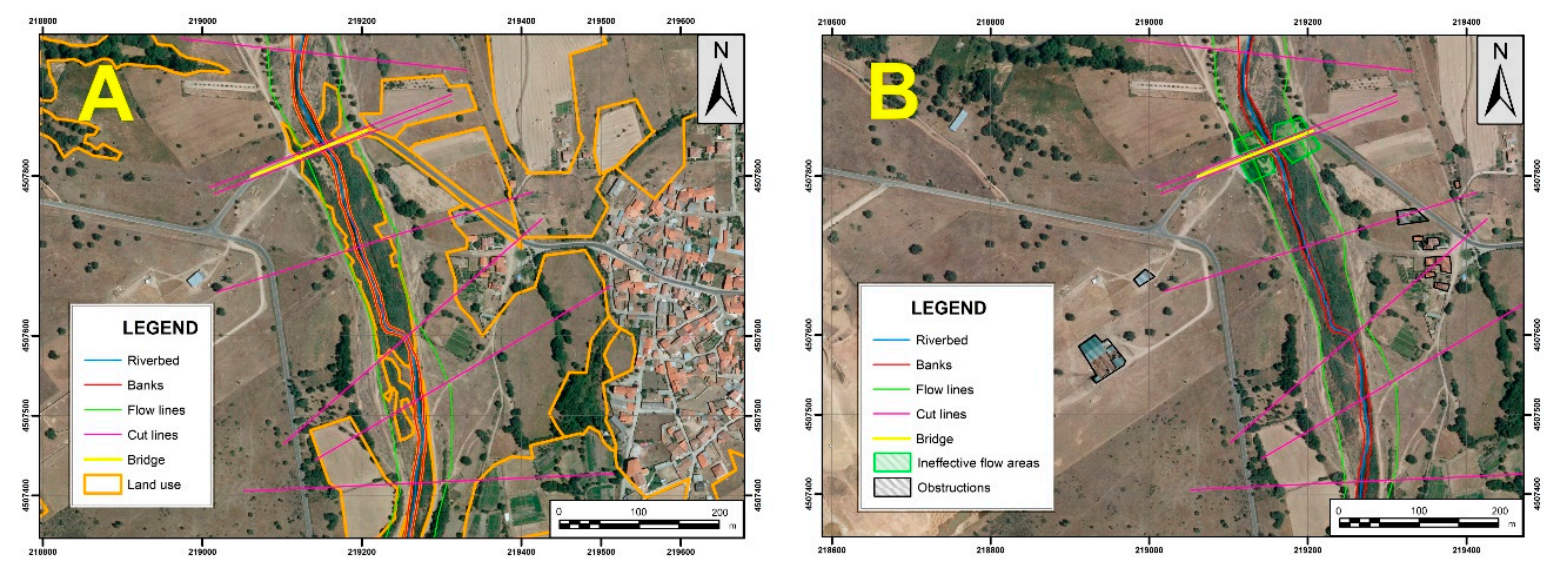

Figure 6. Digitalization of (A) land use; (B) the ineffective flow areas and obstructions.

The land uses taken into consideration were: agricultural crops (0.05), grasslands (0.045), forest and shrubs (0.09), riverbeds (0.04), industrial (0.1), residential (0.08), and urban (0.09).

Another surface element that defines the geometry of the riverbed is the areas of ineffective flow (Figure 6B), that is to say, areas where there is an accumulation of water and the flow rate is zero. In the stretch of the Yeltes River, this type of area was not found. However, there was one area found in the Morasverdes river where stagnation of water could be identified, corresponding to the areas situated before and after the walls on both sides of the bridge, blocking water flow.

In the study area, there were also some elements that, although not included in the information regarding the land, could cause an obstruction of flow in the flood areas.

On both sides of the Morasverdes' riverbeds, there were industrial units and houses found close to the bridge, which were considered as obstruction elements, capable of blocking flow (Figure 6B).

\subsubsection{Importing and Editing the Geometric Information of the Riverbed in HEC-RAS}

Before beginning the editing and correcting of the geometric information of the riverbed using HEC-RAS, it is necessary to first import this data from ArcGIS. The information and longitudinal reference is incorporated into the axis and the flow lines, and the information regarding land morphology, the distribution of $n$ values, infrastructures, etc., together with the transversal sections and the section of the bridge, is visualized with the program HEC-RAS (Figure 7A). The geometric structure of the bridge was also edited using this program (Figure 7B). 


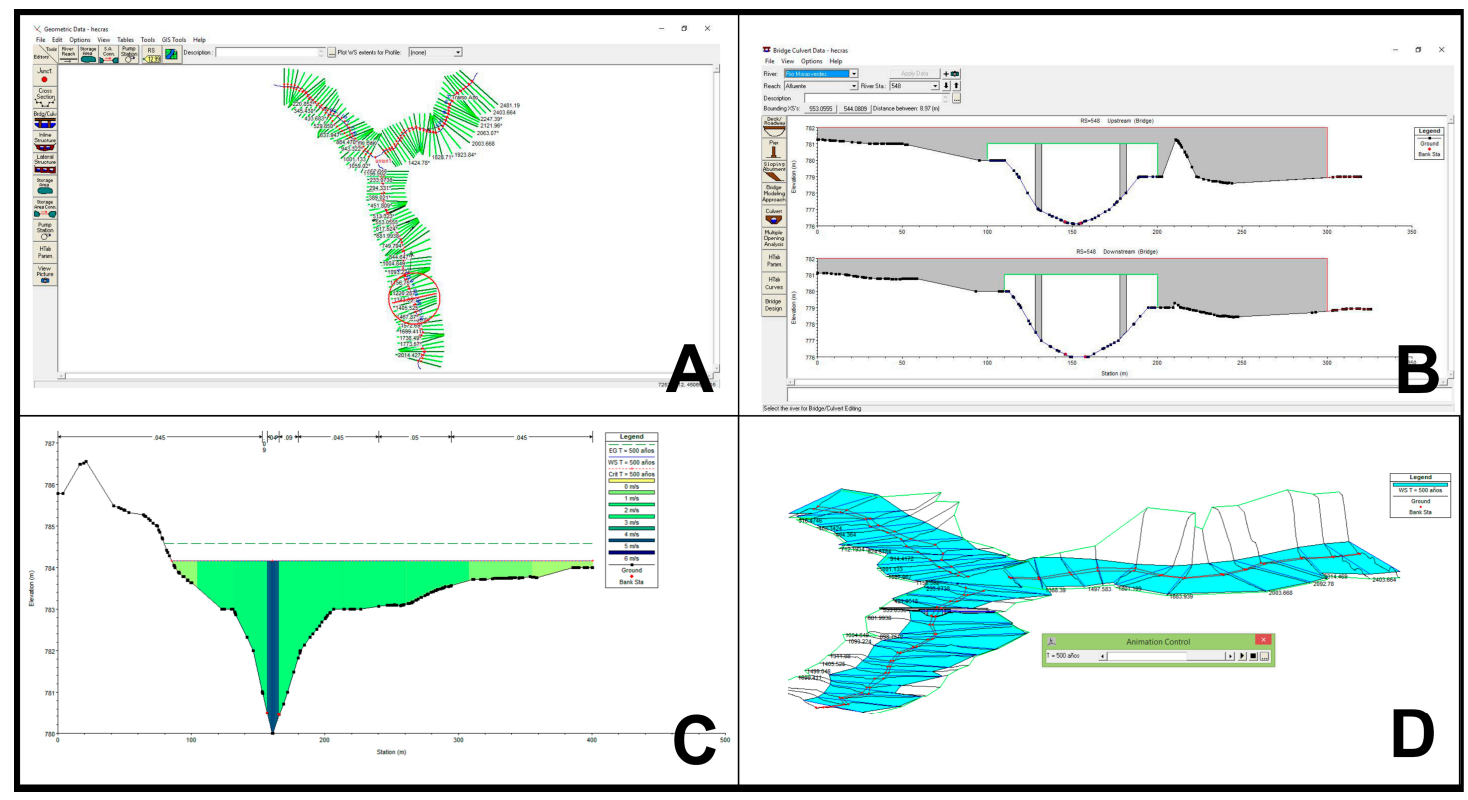

Figure 7. Processes in HEC-RAS: (A) Riverbed geometry and view of the HEC-RAS interface program; (B) definition of the geometric structure of the bridge upstream and downstream; (C) rate profiles for steady flow conditions; and (D) an example of the results of the three-dimensional models of the analysis of flooding for each time return in HEC-RAS.

\subsubsection{Simulation of Flooding Processes in HEC-RAS}

The simulation is carried out by taking into account that some of the conditions of steady flow had constant velocities. The system is subcritical, corresponding to a slow flow, and the conditions of downstream contours are considered. Also, a "normal depth" is selected because the slope along the riverbed is known, and because the flow conditions are close to being uniform. Lastly, the design flow rates are included within the HEC-RAS editing toolbar, in the "Steady Flow Data" section. Once the simulation is successfully achieved, the rate profiles for each of the transversal sections are obtained (Figure 7C), as well as the three-dimensional flood models in steady flow conditions (Figure 7D).

The next phase also required importing the work carried out using HEC-RAS into Arc-Map, to visualize the obtained results.

\subsection{Environmental Diagnostics and Risk, Vulnerability, and Exposure Evaluation}

The most common method used to define flood risk consists of calculating the hazard, that is, the physical and statistical aspects of the actual flood (for example: flood return period, the extent and depth of the flood, and flow rate), and the level of vulnerability, the exposure of people and things to the flood, and the susceptibility of the elements at risk of suffering damage due to flooding. This definition has also been adopted by the EU Floods Directive (2007). Hence, it is comprised of three parameters [17]: hazard, vulnerability, and exposure, and is calculated using the following equation (Equation (1)):

$$
\text { Risk }=\text { Hazard } \times \text { Vulnerability } \times \text { Exposure }
$$

The determination of the risk of extraordinary floods in the stretches of the Yeltes and Morasverdes rivers, which are the object of study in this project, have allowed an environmental diagnostics cartography to be generated, establishing a risk zoning, based on the associated impact. The flow rates indicated in the previous sections have been estimated on the basis of the area's mean precipitation values. This is taken into account as a normal value, i.e., data statistically processed from sequences of consecutive values of more than 20 years. The hydro-meteorological calculations obtained predict 
floods that are caused by centers of action atmospheric (storms). The extraordinary flow generated is superimposed on the digital model of elevations observing the behavior of water on the ground. Thus, the zoning of each area's flood risk can be extrapolated to 2, 100, and 500 years. This method was followed with the aim of designing the environmental diagnostic cartography of the area. In the first hazard map, the following zones could be differentiated:

(1) High hazard zone: represented in red on the map, and signifies a high risk to humans, due to the depth of the water sheet $(>1 \mathrm{~m})$, the current rate $(>1 \mathrm{~m} / \mathrm{s})$, or the combination of both. This area is equivalent to the floodable area during a two-year return period and thus, presents a high probability of flooding.

(2) Medium hazard zone: represented in orange on the map, and is susceptible to frequent flooding; however, the depth and current rate do not present a risk to human life $(<1 \mathrm{~m}$ and $<1 \mathrm{~m} / \mathrm{s}$, respectively). This area is equivalent to the floodable area of a 100-year time return and thus, presents a medium probability of flooding.

(3) Low hazard zone: represented in yellow on the map, and corresponds to those land sectors that present extraordinary and infrequent flooding. This area is equivalent to a 500-year time return and thus, presents a low probability of flooding.

In order to produce a vulnerability and exposure cartography, the cover and land use included within the study area, were taken into account. Additionally, to evaluate the weighting coefficient, a numeric value (1-3, Table 2$)$ was assigned to both the vulnerability and exposure, which varied according to the different land covers, in order to indicate the susceptibility of these variables to the risk of flooding. To achieve this, a quantitative value was assigned to each land use category, according to the human presence associated with each one (Tables 3 and 4), as shown in the following tables:

Table 2. Criteria for assessing different land uses.

\begin{tabular}{clcc}
\hline \multicolumn{4}{c}{ Vulnerability and Exposure } \\
\hline Criteria & \multicolumn{1}{c}{ Description } & Value & Meaning \\
\hline Urban areas & Areas with high risk due to constant human presence & 3 & HIGH \\
Infrastructures & Areas with medium risk due to sporadic human presence & 2 & MEDIUM \\
Environment & Areas with low risk due to being inhabitable & 1 & LOW \\
\hline
\end{tabular}

Table 3. Assigning values according to land use.

\begin{tabular}{lclc}
\hline \multicolumn{1}{c}{ Vulnerability and Exposure } \\
\hline \multicolumn{1}{c}{ Land Use } & Value & Land Use & Value \\
\hline Continuous urban areas & 3 & Grass and meadows & 1 \\
Discontinuous urban areas & 3 & Crop mosaic & 1 \\
Industrial or commercial areas & 2 & Mainly agricultural land & 1 \\
Road and rail networks and associated land & 2 & Agroforestry system & 1 \\
Airports & 2 & Broadleaf forests & 1 \\
Mining extraction areas & 2 & Coniferous forest & 1 \\
Construction areas & 2 & Mixed forest & 1 \\
Sporting and recreational facilities & 2 & Natural pasture & 1 \\
Rainfed farmland & 1 & Sclerophyllous scrub & 1 \\
Permanently irrigated land & 1 & Transitional woodland scrub & 1 \\
Olive grove & 1 & Courses and water bodies & 1 \\
\hline
\end{tabular}

The final cartography is the Environmental Diagnostic map, which is the result of the flood risk analysis carried out in this study, in which five impact categories (very high, high, medium, low, and very low) have been considered: 
Table 4. Impact matrix.

\begin{tabular}{ccccc}
\hline & & \multicolumn{3}{c}{ Vulnerability and Exposure } \\
\cline { 3 - 5 } & & High & Medium & Low \\
\hline \multirow{4}{*}{ Risk } & High & Very high & High & Medium \\
& Medium & High & Medium & Low \\
& Low & Medium & Low & Very low \\
\hline
\end{tabular}

\section{Results and Discussion}

Once the results were imported into Arc-Map, the flood calculation layers were generated in the TIN format, and we were also able to visualize the layers, to obtain the following isobaths (Figure 8A-C) and isotach maps (Figure 8D-F) for each of the 2-, 100-, and 500-year return periods, respectively. This information provided details regarding the height reached by the watersheet, the flooded surfaces [18,19], the water depth, and the distribution of the flow rates, for each return period.
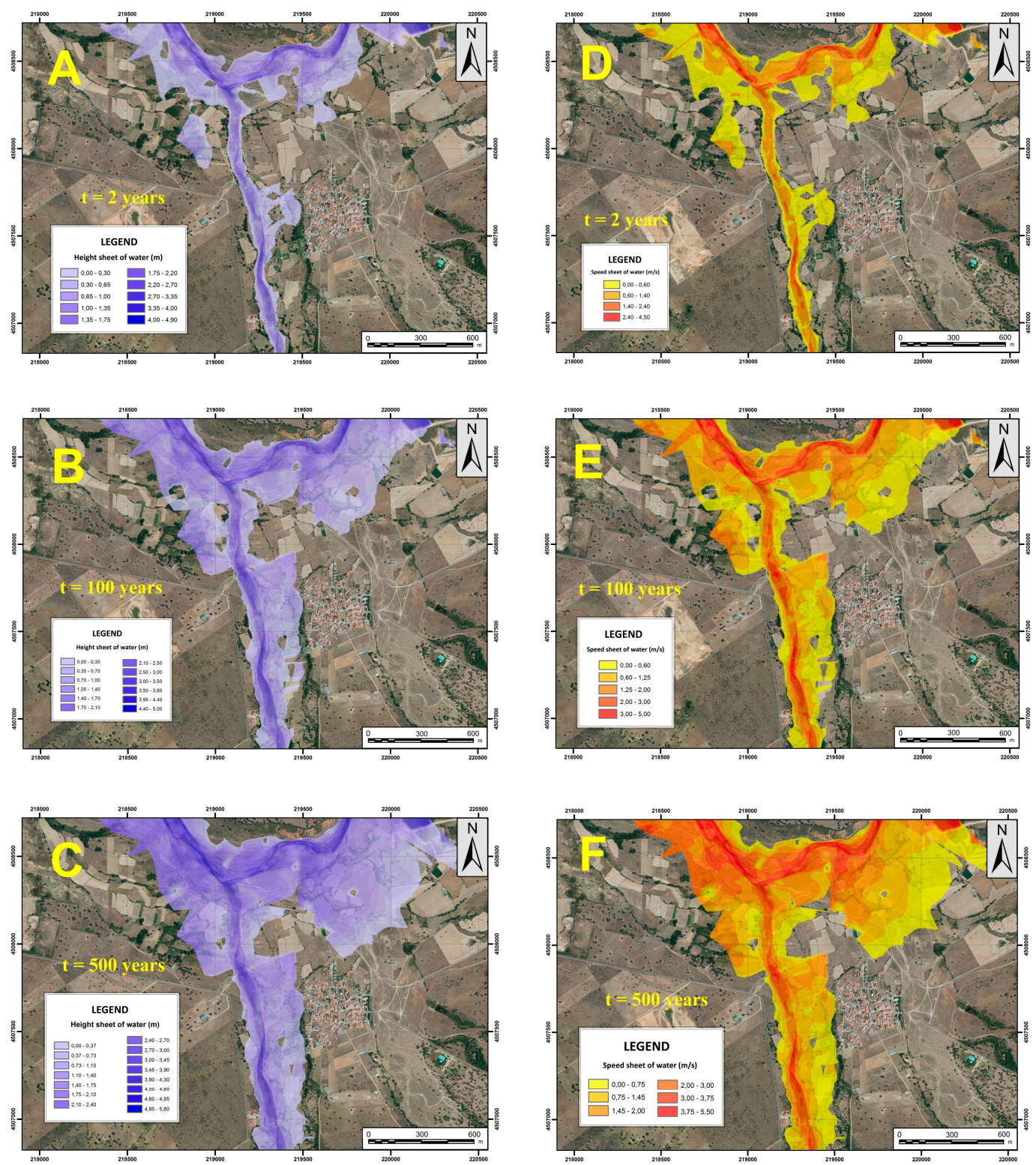

Figure 8. (A-C) Depth of the water surface (isobaths) for 2, 100, and 500 years; and (D-F) distribution of flow rates (isotachs) for 2, 100, and 500 years. 
The results of the model have been presented using a three dimensional representation of the flooded area, on top of the zone's orthophotograph, using ArcScene, for each of the return periods considered (Figure 9A-C).

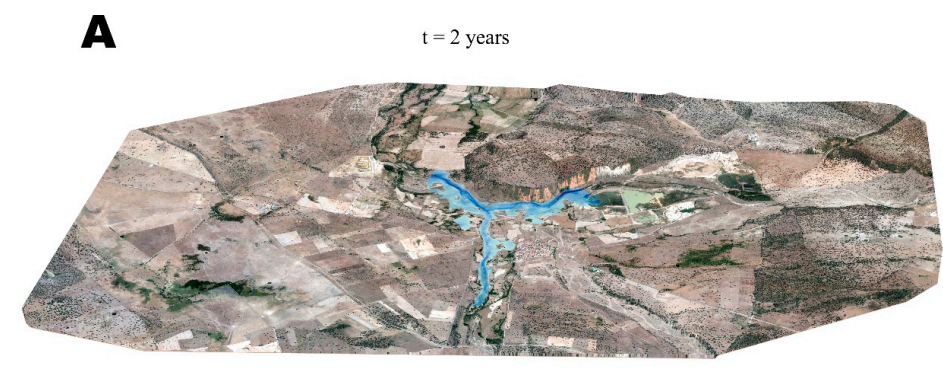

B $\quad t=100$ years

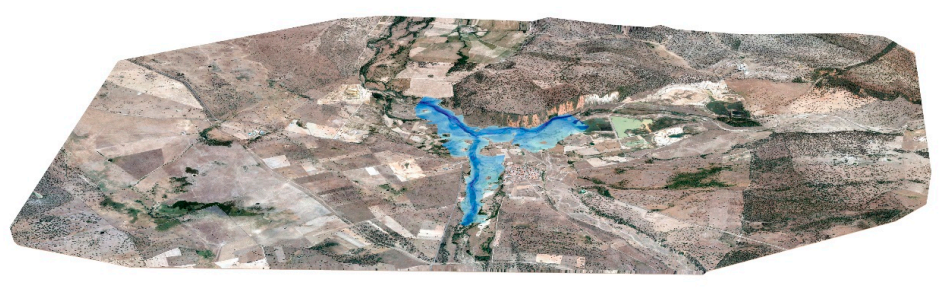

C $\quad t=500$ years

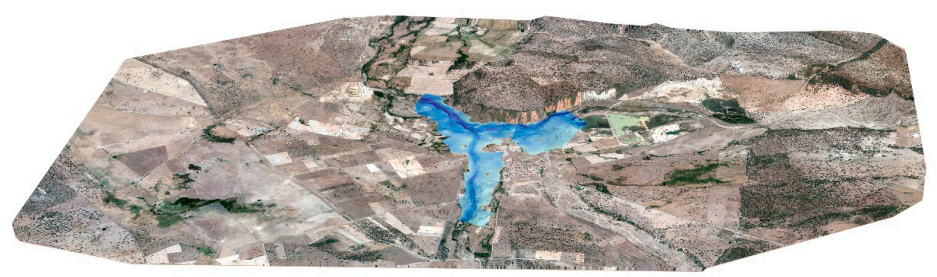

Figure 9. 3D models of the analysis of flooding for each return period (A) 2 years; (B) 100 years; (C) 500 years in ArcScene.

Regarding the final cartographies (Figure 10), it must be mentioned that, in the danger map (Figure 10A). The highest risk was observed in areas closest to the riverbed, since the watersheet depth was greater in the riverbed axis, similar to what occurs for current flow rates. The medium-risk areas, in orange, are situated farther from the riverbed axis, and the areas in yellow, located at the edge of the riverbed, are those that present a low risk.

Regarding the vulnerability and exposure cartography (Figure 10B), it is worth commenting that, for the different land covers, mainly farm lands, pastures, and woodlands, most of the mapped area had been catalogued as a zone of low vulnerability and exposure, and is represented in green. In addition, in the upper right corner, there is an active gravel area that is located relatively close to the Yeltes riverbed, which has been assigned a grade of medium vulnerability and exposure, colored in yellow. Also, the urban areas that have municipal infrastructures and which are considered to be zones of high vulnerability and exposure, are presented in red. Finally, it must be noted that within the environmental diagnostic map (Figure 10C), comprising a total area of $1.28 \mathrm{~km}^{2}$, there is an area of $0.11 \mathrm{~km}^{2}$ with a very high impact, shown in red, representing approximately $9 \%$ of the total area of the map illustrating the risk of floods. The area is mainly situated in the zone containing the bridge where the Morasverdes river flows, and does not correspond to the inhabited areas located close to the riverbed. 

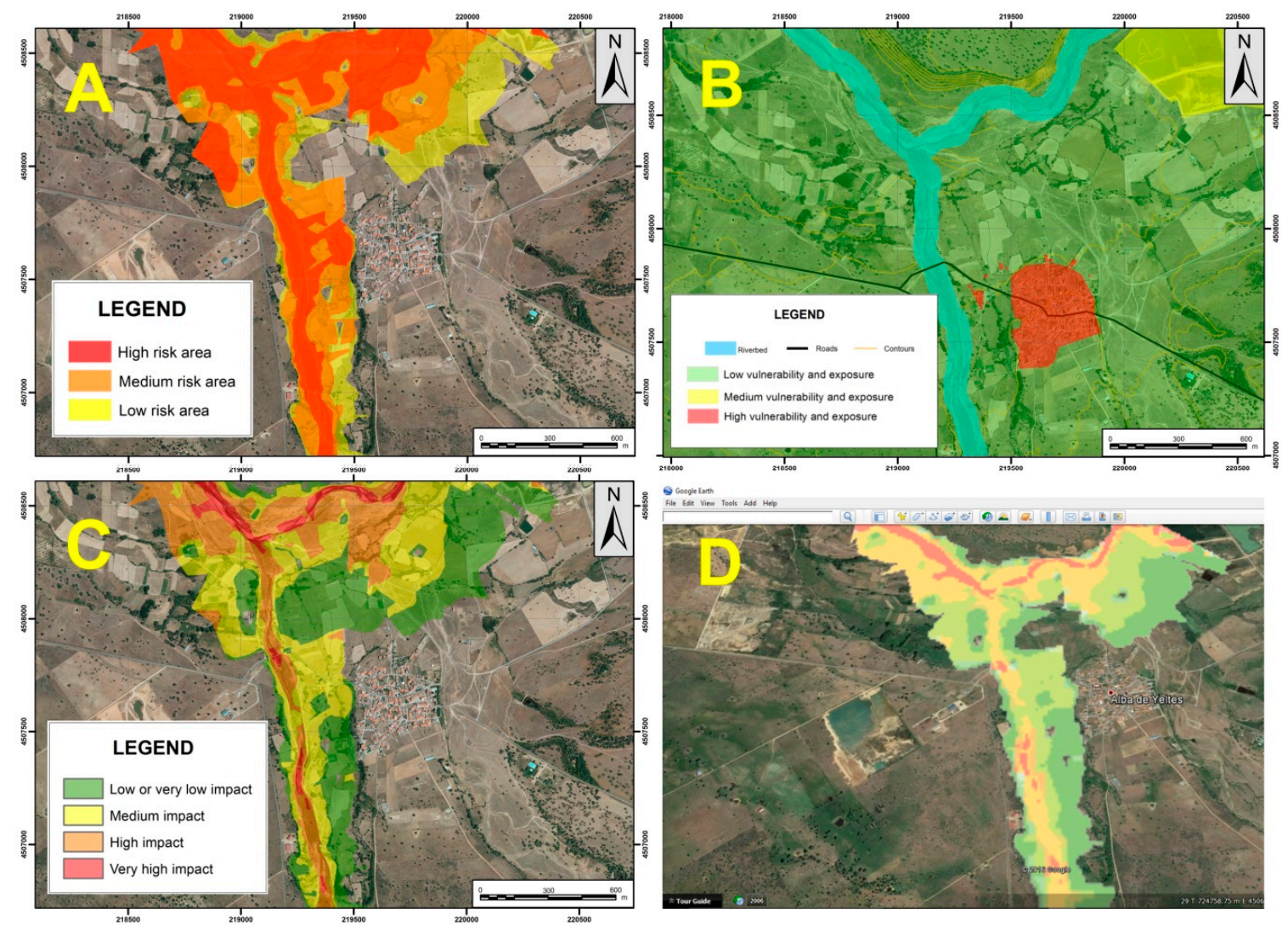

Figure 10. (A) Risk map; vulnerability and (B) exposure map; (C) environmental diagnostic map of flood risk and (D) the view of the environmental diagnostic map using Google Earth.

The surface characterized as high impact, represented in orange, also occupies areas very close to the riverbed, and principally on the left margin of the Yeltes River. In some cases, flooded farmland can be appreciated, although the inhabited areas are not affected, diminishing the degree of impact. This zone of high impact occupies a surface area of $0.27 \mathrm{~km}^{2}$, which represents $21 \%$ of the total diagnostic surface.

The zone occupying a large extent of the total area that presents a risk of floods, is characterized with a medium impact level, and is represented in yellow on the map. It has a surface area of $0.44 \mathrm{~km}^{2}$, comprising $34 \%$ of the total area, and occupies both the riverbed and distant areas, affecting other cultivation plots. There are also levels of medium impact, in an area where some of the buildings are located very close to the Morasverdes riverbed, specifically on the left bank. However, none of the inhabited areas are affected.

Finally, the zones that present low and very low levels of impact, represented on the map in green, are the areas farthest away from the riverbed, and constitute $0.46 \mathrm{~km}^{2}$; approximately $36 \%$ of the total area.

It should also be mentioned that all of the layers in the shape format are easily interoperable with the other platforms, such as Google Earth (Figure 10D), although in this case, the format needs to be changed to either KML or KMZ.

\section{Conclusions}

This flood risk analysis of the town of Alba de Yeltes, and the analysis of the hazard, vulnerability, and exposure in the face of extraordinary flooding, using the application GIS, has permitted flood risk zoning to be established, according to the impact produced by floods in the outskirts of the village. 
The cartographies generated have permitted an environmental diagnostic of the extraordinary flooding processes, and the areas with an associated impact of the risk of floods; this tool is essential for the development of the effective and rational management of the risk of floods. This analysis has illustrated the areas with a potential risk of flooding, which include the built-up areas inside the town center that are close to the Morasverdes riverbed, and the floodplains and terraces of the Yeltes River.

The re-evaluation of outdated urban planning, as well as the implementation of a series of measures to mitigate the risk of floods, is necessary. This cartographic method generates risk maps that allow dangerous areas to be identified, which may be useful in future urban planning, minimizing the risk of flooding at a local scale, with only minor costs in the first stages of municipal planning.

Acknowledgments: This work has been supported by the USAL research projects CGL2012-37281-C02.01, CGL2015-67169-P and CGL2015-69919-R (MINECO-FEDER).

Author Contributions: For research articles work presented in this paper is a collaborative development by all authors. Sergio Veleda and Antonio Martínez-Graña processed the data in GIS and Hec-Ras. Fernando Santos-Francés and Marco Criado processed the thematic map. Javier Sánchez-San Roman processed the hidrologic value. The manuscript was written, revised, and corrected by all co-authors.

Conflicts of Interest: The authors declare no conflict of interest.

\section{References}

1. Theilen-Willige, B.; Savvaidis, P.; Tziavos, I.N.; Papadopoulou, I. Remote Sensing and Geographic Information Systems (GIS) contribution to the inventory of infrastructure susceptible to earthquake and flooding hazards in North-Eastern Greece. Geosciences 2012, 2, 203-220. [CrossRef]

2. Lewin, J. Enlightenment and the GM floodplain. Earth Surf. Process. Landf. 2013, 38, 17-29. [CrossRef]

3. Thumerer, T.; Jones, A.P.; Brown, D. A GIS based coastal management system for climate change associated flood risk assessment on the east coast of England. Int. J. Geogr. Inf. Sci. 2000, 14, 265-281. [CrossRef]

4. Van der Knijff, J.M.; Younis, J.; de Roo, A.P.J. LISFLOOD: A GIS-based distributed model for river basin scale water balance and flood simulation. Int. J. Geogr. Inf. Sci. 2010, 24, 189-212. [CrossRef]

5. Welsh, W.D.; Vaze, J.; Dutta, D.; Rassam, D.; Rahman, J.M.; Jolly, I.D.; Teng, J. An integrated modelling framework for regulated river systems. Environ. Model. Softw. 2013, 39, 81-102. [CrossRef]

6. Cheong, T.S.; Felix, M.L.A.; Jeong, S.M. Development of GIS-based disaster assessment system to reduce flood risks in urbanized creeks. Desalin. Water Treat. 2014, 52, 2817-2825. [CrossRef]

7. Vojtek, M.; Vojteková, J. Flood hazard and flood risk assessment at the local spatial scale: A case study. Geomat. Nat. Hazards Risk 2016, 7, 1-20. [CrossRef]

8. Mebarki, A.; Valencia, N.; Salagnac, J.L.; Barroca, B. Flood hazards and masonry constructions: A probabilistic framework for damage, risk and resilience at urban scale. Nat. Hazards Earth Syst. Sci. 2012, 12, 1799-1809. [CrossRef]

9. Martínez-Graña, A.M.; Goy, J.L.; Zazo, C. Cartographic procedure for the analysis of eolian erosion hazard in Natural Parks (Central System, Spain). Land Degrad. Dev. 2012, 26, 110-117. [CrossRef]

10. Martínez-Graña, A.M.; Goy, J.L.; Zazo, C. Water and wind erosion risk in natural parks. A case study in "Las Batuecas-Sierra de Francia" and "Quilamas" protected parks (Central System, Spain). Int. J. Environ. Res. 2014, 8, 61-68.

11. Martínez-Graña, A.M.; Goy, J.L.; Zazo, C.; Yenes, M. Engineering Geology Maps for Planning and Management of Natural Parks: "Las Batuecas-Sierra de Francia” and "Quilamas" (Central Spanish System, Salamanca, Spain). Geosciences 2013, 3, 46-62. [CrossRef]

12. Silva, P.G.; López, M.; Roquero, E.; Huerta, P.; Martínez-Graña, A.M. Chronology of fluvial terrace sequences for Large Atlantic Rivers in the Iberian Peninsula (Upper Tagus and Duero drainage basins, Central Spain). Quat. Sci. Rev. 2016. [CrossRef]

13. Martínez-Graña, A.M.; Goy, J.L.; Zazo, C. Dominant soil map in "Las Batuecas-Sierra de Francia" and "Quilamas" nature parks (Central System, Salamanca, Spain). J. Maps 2015, 11, 371-379. [CrossRef]

14. Martínez-Graña, A.M.; Goy, J.L.; Zazo, C. Geomorphological applications for susceptibility mapping of landslides in natural parks. Environ. Eng. Manag. J. 2016, 15, 1-12. 
15. Castronova, A.M.; Goodall, J.L.; Ercan, M.B. Integrated modeling within a hydrologic information system: An OpenMI based approach. Environ. Model. Softw. 2013, 39, 263-273. [CrossRef]

16. Kulkarni, A.T.; Mohanty, J.; Eldho, T.I.; Rao, E.P.; Mohan, B.K. A web GIS based integrated flood assessment modeling tool for coastal urban watersheds. Comput. Geosci. 2014, 64, 7-14. [CrossRef]

17. Martínez-Grana, A.M.; Boski, T.; Goy, J.L.; Zazo, C.; Dabrio, C.J. Coastal-flood risk management in central Algarve: Vulnerability and flood risk indices (South Portugal). Ecol. Indic. 2016, 71, 302-316. [CrossRef]

18. Apel, H.; Aronica, G.T.; Kreibich, H.; Thieken, A.H. Flood risk analyses-How detailed do we need to be? Nat. Hazards 2009, 49, 79-98. [CrossRef]

19. Pradhan, B.; Hagemann, U.; Tehrany, M.S.; Prechtel, N. An easy to use ArcMap based texture analysis program for extraction of flooded areas from TerraSAR-X satellite image. Comput. Geosci. 2014, 63, $34-43$. [CrossRef] 